\title{
Conservative treatment of cytomegalovirus colitis with bowel perforation in an immunocompetent patient: case report and review of literature
}

\author{
Kyoung Sik Nam, Hee Ug Park, Min Gi Park, Su Ho Park, Ji Yeon Hwang, Dong Kyu Kim, Sung Jun Kim \\ Division of Gastroenterology, Department of Internal Medicine, Maryknoll Medical Center, Busan, Korea
}

\begin{abstract}
Cytomegalovirus (CMV) colitis, which is rare in an immunocompetent patient, was encountered in a 67-yearold man who was admitted due to persistent diarrhea. The first diagnostic tool was colonoscopy, which showed multiple ulcers from cecum to rectum. The secondary tool was CMV polymerase chain reaction, and CMV colitis was diagnosed. Intravenous ganciclovir therapy was administered, which resulted in improvement of diarrhea and ulcers throughout the colon were healed. Asymptomatic colon perforation was detected during diagnostic testing, which improved over the conventional treatment. CMV colitis is rare in immunocompetent patients, but it is essential for the differential diagnosis.
\end{abstract}

Keywords: Cytomegalovirus; Colitis; Immunocompetence; Perforation

\section{INTRODUCTION}

Cytomegalovirus (CMV) colitis usually affects immunocompromised patients such as those with human immunodeficiency virus (HIV) infection or transplant recipients [1]. It has also been reported in patients with steroid dependency or chronic renal failure [2,3]. In immunocompetent patients it is usually asymptomatic and does not require treatment. However reports of CMV colitis affecting immunocompetent persons [4,5], often presenting complications which warrant surgical therapy, have increased. We encountered a rare case involving perforated CMV colitis in an immunocompetent patient whose symptoms improved with conservative treatment. We report here on this case along with a review of the relevant literature.

Received: July 2, 2015, Revised: September 1, 2015

Accepted: September 7, 2015

Corresponding Author: Hee Ug Park, Division of Gastroenterology, Department of Internal Medicine, Maryknoll Medical Center, 121 Junggu-ro, Jung-gu, Busan 48972, Korea

Tel: +82-51-461-2432, Fax: +82-51-441-6950

E-mail: drhwpark@naver.com

\section{CASE}

A 67-year-old man was admitted with a complaint of diarrhea for 1 month. He had no past medical history or any conditions associated with immunosuppression. He was a sailor and he was on board when the symptoms presented. He denied any symptoms except diarrhea. Despite receiving treatment for 3 weeks in Abuzinadah hospital in Saudi Arabia, diarrhea persisted.

At the time of admission, his body weight was $58 \mathrm{~kg}, 8 \mathrm{~kg}$ less than his usual weight. His vital signs showed body temperature of $36.5^{\circ} \mathrm{C}$, heart rate of 66 beats $/ \mathrm{min}$, and blood pressure of 120/80 mmHg. On physical examination, severe dehydration was detected, but other findings including abdomen distension, tenderness, or rebound tenderness were not observed. Laboratory data showed a white blood cell count 11,400 $/ \mathrm{mm}^{3}$, hemoglobin $44.0 \mathrm{~g} / \mathrm{dL}$, hematocrit $32.6 \%$, platelet count $328,000 / \mathrm{mm}^{3}$, total protein $5.7 \mathrm{~g} / \mathrm{dL}$, albumin $3.3 \mathrm{gm} / \mathrm{dL}$, aspartate transaminase/alanine transaminase $13 / 6 \mathrm{IU} / \mathrm{L}$, total bilirubin $1.17 \mathrm{mg} / \mathrm{dL}$, blood urea nitrogen $15.6 \mathrm{mg} / \mathrm{dL}$, and creatinine $0.7 \mathrm{mg} / \mathrm{dL}$. Serum CMV immunoglobulin (Ig) G was positive, and CMV IgM negative. HIV antibody, antigen of

Copyright (C) 2017 Yeungnam University College of Medicine

This is an Open Access article distributed under the terms of the Creative Commons Attribution Non-Commercial License (http://creativecommons.org/licenses/by-nc/4.0/) which permits unrestricted non-commercial use, distribution, and reproduction in any medium, provided the original work is properly cited. 
the hepatitis $\mathrm{B}$ virus, and antibody to hepatitis $\mathrm{C}$ virus were not detected. Blood and stool cultures were negative and Clostridium difficile toxin was not detected. Chest radiography (Fig. 1) showed free air in the abdomen. Abdominal CT (Fig. 2) showed bowel dilatation and loss of haustral folds on the whole bowel, particularly the transverse colon and gastric ulcer, which was suspected perforation. However, symptoms of peritonitis were not observed. Although surgery was considered as a primary option for treatment due to his poor physical status including severe dehydration and poor general condition, it was considered dangerous and difficult. Instead, we decided on conservative treatment. After 2 days, free air was not detected on chest X-ray.

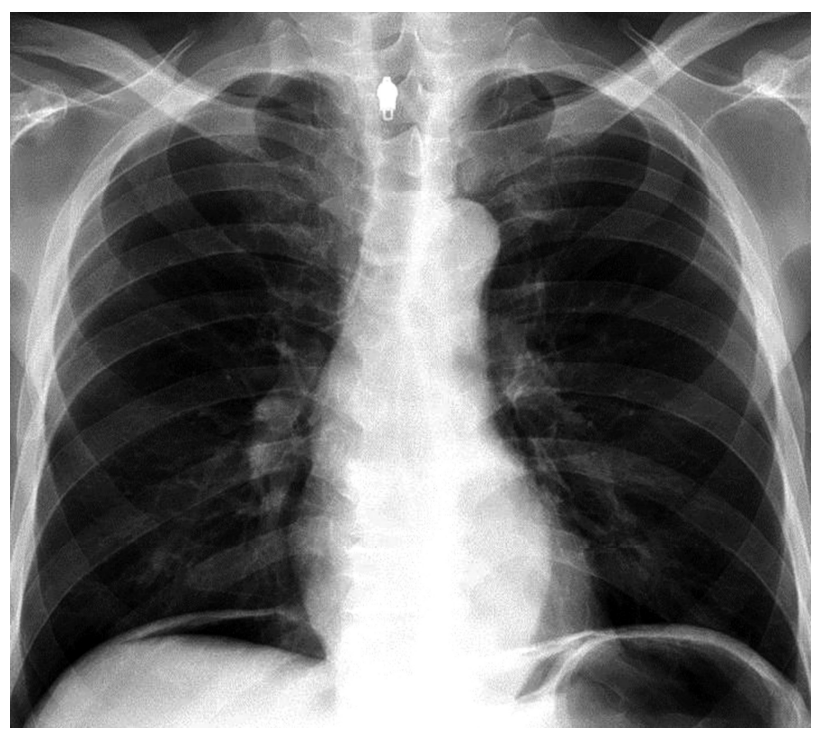

Fig. 1. Chest radiography shows free air in abdomen.

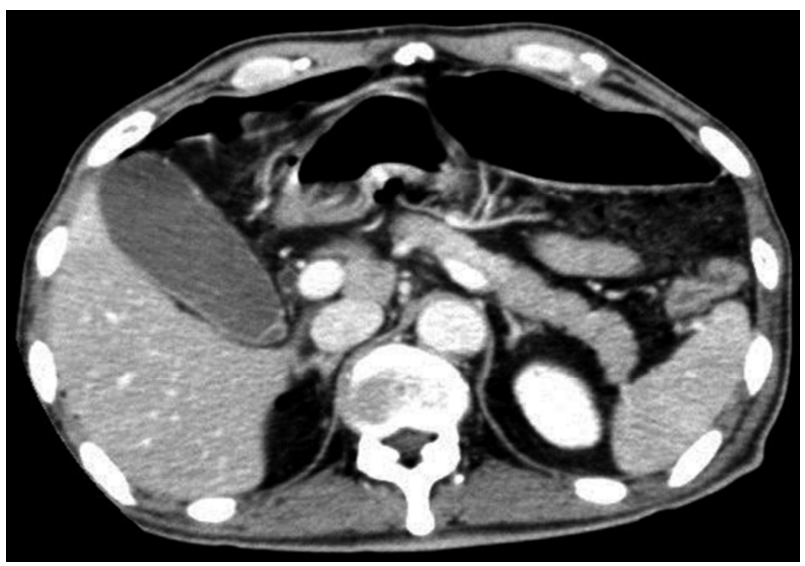

Fig. 2. Abdominal CT shows pneumoperitoneum which is to doubt the perforation.
On his third day of hospitalization, colonoscopy was performed which showed multiple deep geographic ulcerations from ascending colon to rectum (Fig. 3). The histology showed multiple giant cells with intranuclear inclusion bodies, consistent with CMV-infected cells (Fig. 4). CMV-polymerase chain reaction analysis on biopsy and blood were positive. On gastroscopy, no perforations were found in areas where they might have been located. Based on these evidences, the patient was diagnosed with CMV colitis with bowel perforation.

Intravenous ganciclovir therapy was initiated $(290 \mathrm{mg}$ twice a day) and maintained for 2 weeks. Subsequently, his symptoms improved and follow up colonoscopy showed an early normalized colon (Fig. 5). He was discharged with no recurrence of diarrhea during 9 months of follow-up.

\section{DISCUSSION}

$\mathrm{CMV}$ is a double-stranded DNA virus belonging to the herpes virus family. CMV is excreted through body fluids, including saliva, respiratory secretions, urine, blood, breast milk, and semen, and transmitted by close personal contact; thus, CMV infections are common worldwide. The risk of exposure to $\mathrm{CMV}$ increases with age and geographic location. In China, more than 90 percent of adults are seropositive for CMV, while approximately 60 percent of the general populations in the United States have serologic evidence of prior infection with CMV [6].

CMV frequently affects immune-deficient hosts such as those undergoing chemotherapy, transplant or acquired immunodeficiency syndrome [7]. Immunocompetent hosts may develop CMV colitis, and according to the meta-analysis of outcome of CMV colitis in immunocompetent hosts [8], most patients were $>55$ years old, with a trend toward decreased survival for male patients. Infection is usually asymptomatic but can produce symptoms similar to those of infectious mononucleosis, including fever, myalgias, cervical lymphadenopathy, and elevated liver enzyme [7]. However immune compromised hosts, such as those undergoing chemotherapy, transplant or whose with acquired immunodeficiency syndrome, appear to present with more severe symptoms [8,9]. Some studies have also reported an increased risk of CMV-related morbidity and mortality in immunocompromised, critically ill patients [10]. Risk factors of CMV colitis include age ( $>55$ years), male sex, and immunomodulating conditions such as 

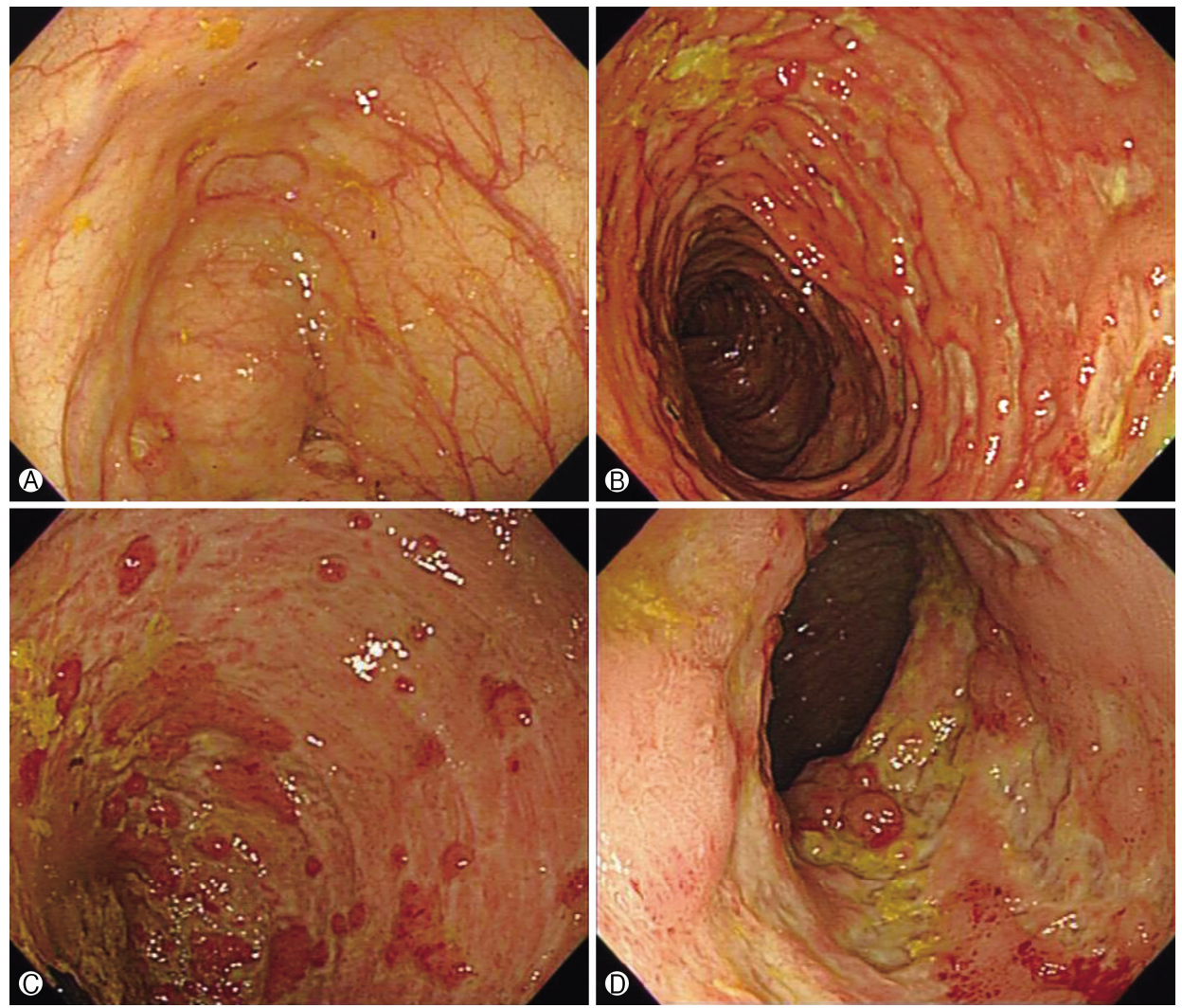

Fig. 3. First colonoscopy finding (on 3rd day) shows multiple geographic deep ulcerations (A, cecum; $\mathrm{B}$, transverse colon; C, sigmoid colon; $\mathrm{D}$, rectum).

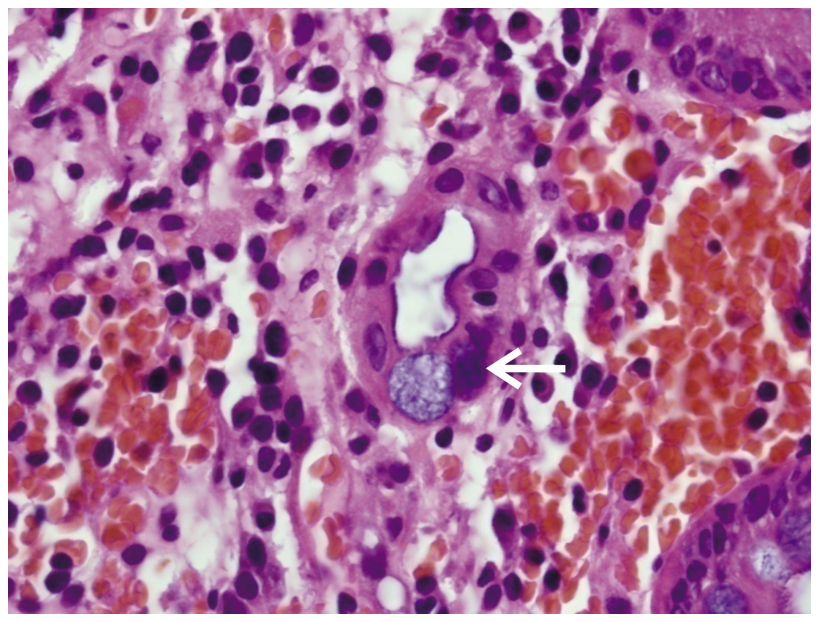

Fig. 4. Microscopic finding of the colon. Cytomegalovirus inclusion bodies are seen in the glandular epithelial cells (arrow) (H\&E stain, $\times 400)$.

pregnancy, chronic renal failure, untreated hematological malignancy, and diabetes. Such risk factors adversely influence survival [11].

Rafailidis et al. [12] reported that vulnerable organs in CMV infection include the gastrointestinal tract, lung, retina, liver, and central nervous system. The pathogenesis of CMV related GI disease is believed to be submucosal vasculitis resulting in thrombosis with ischemia leading to ulceration, bowel wall thickening and occasional gangrene or perforation [13]. Goodman et al. [14] proposed two mechanisms of CMV as a factor leading to perforation; viral infection of the colonic epithelium might result in mucosal erosion and ulceration eventually leading to perforation. Another alternative mechanism would be $\mathrm{CMV}$ infection of granulation tissue in a pre-existing ulcer causing exacerbation of the inflammation, further ulceration, and eventually perforation.

There are several methods for diagnosis of CMV. In cases of suspected CMV colitis, gastroscopy is performed and we look for the typical owl's eye on histology. It shows high specificity, but low sensitivity, thus immunohistochemistry or simple hematoxylin and eosin can be used to improve sensitivity. Other laboratory methods include serology, specific intrathecal antibody production, and direct detection of CMV pp65 antigen in blood [12,15]. Serology is not sufficient to make 


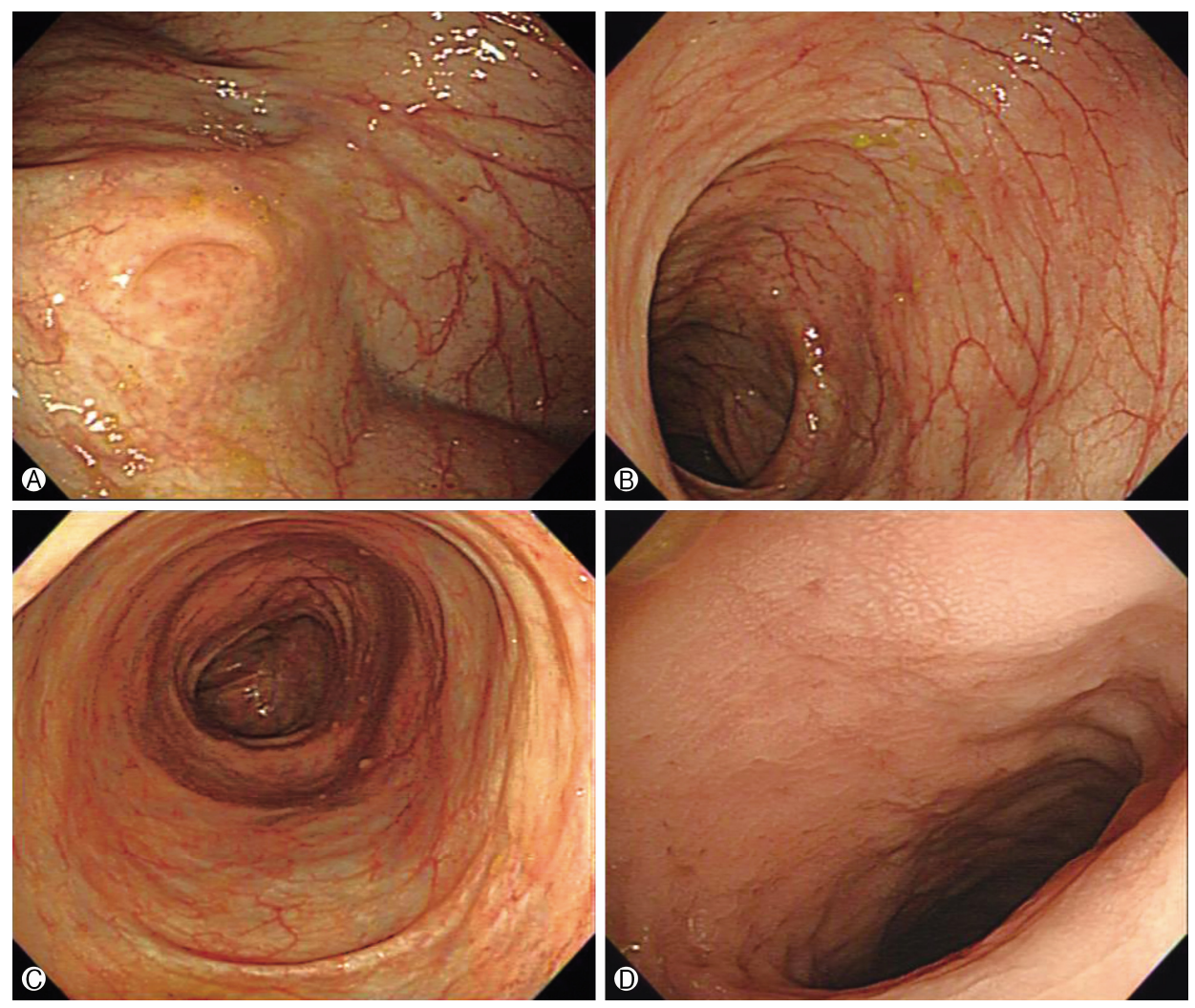

Fig. 5. Third colonoscopy finding (on 63rd day) shows almost complete mucosal healing after ganciclovir therapy (A, cecum; B, transverse colon; C, sigmoid colon; D, rectum).

a timely diagnosis of $\mathrm{CMV}$ infection, and the absence of $\mathrm{CMV}$ IgM antibody may not exclude CMV infection. In our case, CMV IgM antibody was negative, but the diagnosis of CMV colitis was made by pathology results, which showed the typical CMV inclusion indicating active virus production [16].

Ganciclovir is currently recommended as first-line treatment for CMV related disease. Close monitoring of the side effects is essential during ganciclovir treatment. Typical side effects include myelosuppression, central nervous system disorders, hepatotoxicity, and nephrotoxicity [12]. Foscarnet and cidofovir are available for second line treatment in patients not able to tolerate ganciclovir treatment $[17,18]$. Another therapeutic strategy is the elective surgical resection of the inflamed intestine in combination with anti-CMV therapy. Lee et al. [4] reported on an 88 year-old-man admitted with a complaint of diarrhea, occurred ileal perforation and peritonitis. Surgery was performed and CMV colitis was diagnosed by histopathology. He recovered without administration of an anti-virus agent. Admission with diarrhea in an elderly pati- ent was similar to our case, but the difference is that he was improved by surgery without an anti-viral agent.

In our case, the patient had two risk factors, age ( $>55$ years) and male sex. Chest radiography showed free air in the abdomen, thus gastroscopy and colonoscopy were performed; however no perforation focus was found on the stomach or bowels. We assume that healing and blocking of the perforation focus occurred by a natural process. Abdominal pain, abdominal tenderness, and rebound tenderness, typical symptoms of peritonitis were not detected, but body weight was severely reduced, and the patient's general condition was very poor at admission. For this reason, we decided to proceed with a conservative strategy instead of surgical treatment.

Morbidity and mortality associated with perforation from CMV colitis are high. Therefore, timely diagnosis with histologic examination is important. In cases of colon perforation without symptoms of peritonitis due to CMV infection, conservative therapy might be helpful and it should be considered a treatment options. 


\section{CONFLICT OF INTEREST}

No potential conflict of interest relevant to this article was reported.

\section{REFERENCES}

1. Harano Y, Kotajima L, Arioka H. Case of cytomegalovirus colitis in an immunocompetent patient: a rare cause of abdominal pain and diarrhea in the elderly. Int J Gen Med 2015;8: 97-100.

2. Chen YM, Hung YP, Huang CF, Lee NY, Chen CY, Sung $\mathrm{JM}$, et al. Cytomegalovirus disease in nonimmunocompromised, human immunodeficiency virus-negative adults with chronic kidney disease. J Microbiol Immunol Infect 2014;47: 345-9.

3. Pfau P, Kochman ML, Furth EE, Lichtenstein GR. Cytomegalovirus colitis complicating ulcerative colitis in the steroidnaive patient. Am J Gastroenterol 2001;96:895-9.

4. Lee G, Kim NI, Gu JT, Suh JI, Yang CH, Lee CW. A case of cytomegalovirus colitis in an immunocompetent adult. Korean J Gastroenterol 2000;35:649-53. Korean.

5. Kim SW, Cha YJ, Kim MH, Jin MN, Lee JH, Park HJ, et al. Cytomegalovirus colitis with colon perforation and lower gastrointestinal bleeding in a immunocompetent patient. Ewha Med J 2014;37:105-8. Korean.

6. De la Hoz RE, Stephens G, Sherlock C. Diagnosis and treatment approaches of CMV infections in adult patients. J Clin Virol 2002;25(Suppl 2):S1-12.

7. Sissons JG, Carmichael AJ. Clinical aspects and management of cytomegalovirus infection. J Infect 2002;44:78-83.

8. Papadakis KA, Tung JK, Binder SW, Kam LY, Abreu MT,
Targan SR, et al. Outcome of cytomegalovirus infections in patients with inflammatory bowel disease. Am J Gastroenterol 2001;96:2137-42.

9. Gorsane I, Aloui S, Letaif A, Hadhri R, Haouala F, Frih A, et al. Cytomegalovirus ischemic colitis and transverse myelitis in a renal transplant recipient. Saudi J Kidney Dis Transpl 2013;24:309-14.

10. Osawa R, Singh N. Cytomegalovirus infection in critically ill patients: a systematic review. Crit Care 2009;13:R68.

11. Galiatsatos P, Shrier I, Lamoureux E, Szilagyi A. Meta-analysis of outcome of cytomegalovirus colitis in immunocompetent hosts. Dig Dis Sci 2005;50:609-16.

12. Rafailidis PI, Mourtzoukou EG, Varbobitis IC, Falagas ME. Severe cytomegalovirus infection in apparently immunocompetent patients: a systematic review. Virol J 2008;5:47.

13. Spencer SP, Power N. The acute abdomen in the immune compromised host. Cancer Imaging 2008;8:93-101.

14. Goodman ZD, Boitnott JK, Yardley JH. Perforation of the colon associated with cytomegalovirus infection. Dig Dis Sci 1979;24:376-80.

15. Emery VC, Sabin CA, Cope AV, Gor D, Hassan-Walker AF, Griffiths PD. Application of viral-load kinetics to identify patients who develop cytomegalovirus disease after transplantation. Lancet 2000;355(9220):2032-6.

16. Francis ND, Boylston AW, Roberts AH, Parkin JM, Pinching AJ. Cytomegalovirus infection in gastrointestinal tracts of patients infected with HIV-1 or AIDS. J Clin Pathol 1989;42: 1055-64.

17. Ho M. The history of cytomegalovirus and its diseases. Med Microbiol Immunol 2008;197:65-73.

18. Blanshard C, Benhamou Y, Dohin E, Lernestedt JO, Gazzard BG, Katlama C. Treatment of AIDS-associated gastrointestinal cytomegalovirus infection with foscarnet and ganciclovir: a randomized comparison. J Infect Dis 1995;172:622-8. 